\title{
LOW-FREQUENCY FATIGUE AT DIFFERENT MUSCLE LENGTH FOLLOWING INTERMITTENT ECCENTRIC DROP JUMPS IN 12-14 YEAR-OLD BOYS
}

\author{
Vytautas Streckis $^{1}$, Giedrius Gorianovas ${ }^{1}$, Birutè Miseckaitė ${ }^{1}$, Valerija Streckienè ${ }^{2}$, \\ Ronaldas Endrijaitis ${ }^{3}$, Arūnas Krasauskas ${ }^{3}$, Vaidas Mickevičius ${ }^{4}$ \\ Lithuanian Academy of Physical Education", "Versmès" secondary school', Kaunas, Lithuania, The \\ General Jonas Žemaitis Military Academy of Lithuania ${ }^{3}$, Vilnius, Lithuania, Kaunas Technical College 4 , \\ Kaunas, Lithuania
}

Vytautas Streckis. Doctor of Biomedical Sciences. Lecturer at the Department of Track-and-Field Athletics, researcher in Human Motorics Laboratory. The field of scientific research - low frequency muscle fatique (LFMF) of boys.

\begin{abstract}
Low frequency fatigue (LFF) in 12-14 year-old adolescent boys $(n=10)$ doing 75 eccentric jumps performed every $20 \mathrm{~s}$ from a platform $80 \mathrm{~cm}$ high was investigated.

Thus the aim of this study was to find out if LFF manifests itself in the muscles of boys aged 12-14 years doing 75 drop jumps performed every $20 \mathrm{~s}$ at angles of $90^{\circ}$ and $135^{\circ}$ from a platform $80 \mathrm{~cm}$ high. The results of the research have shown that doing 75 eccentric jumps performed every 20 s calls forth LFF in the muscles of boys that is particularly strong and disappears more slowly at a shorter length of the muscle exercised. Thus, the hypothesis as to the sarcomeric origin of $L F F$ in the muscles of boys and men has been confirmed. Besides, the muscles of men of mature age are more resistant to LFF than those of boys. This fact, as well as a more acute pain brought about in the muscles of boys, indicates that the muscles of boys are less resistant to mechanical damage than those of men of mature age.

It is maintained that as a result of the eccentric exercise performed, some portion of the weak sarcomeres gets torn and then the strong sarcomeres, i.e. the ones that develop contraction force have to work at a shorter muscle length. When muscle contraction length is short the sensitiveness of miofibrillas to $\mathrm{Ca}^{2+}$ decreases. It is rather unexpected though that $24 \mathrm{~h}$ after the end of the exercise the force developed by electrostimulation at low frequencies $(20 \mathrm{~Hz})$ is smaller $(p<0.05)$, as compared to the initial force registered at a shorter muscle length. Since after the exercise there was also a decrease in the force developed at a shorter muscle length in particular, the sarcomeres are believed to have been damaged during eccentric exercise.
\end{abstract}

Keywords: electrical stimulation, force, age, muscle damage, stretch-shortening exercise.

\section{INTRODUCTION}

$\mathrm{D}$ oing unaccustomed long-lasting physical exercise, performed in eccentric regime in particular, calls forth muscle fatigue that holds on for $48-72 \mathrm{~h}$ and even longer and is frequently accompanied by muscle pain (Jones et al. 1989; Newham et al., 1983).

LFF may be due to a decrease $(10-20 \mathrm{~Hz})$ in muscle contraction force (MCF), as well as due to the disintegration of the elastic muscle contraction components (Armstrong et al., 1991; Jones et al., 1989). The sensitiveness of myofibrillas to calcium ions $\left(\mathrm{Ca}^{2+}\right)$ is believed to depend on the muscle (sarcomeres) length, i. e. the smaller the amplitude of muscle contraction, the lower sensitiveness to $\mathrm{Ca}^{2+}$ (Stephensson, Wendt, 1984). According to the sarcomeric hypothesis, LFF arises due to a partial damage of sarcomeres that manifests itself more markedly during eccentric physical exercise (Friden, Lieber, 1992; Jones, Round, 1997). It is maintained that doing eccentric exercise brings damage to the weak sarcomeres in the first place, whereas the strong sarcomeres have to contract with a higher amplitude in order for the maximum muscle efforts to be achieved (Jones, Round, 1997). LFF, that arises due to a partial damage of sarcomeres 
during eccentric physical exercise, should increase at a shorter muscle length. It is not clear at all, however, how such a type of fatigue manifests itself in 12-14 year-old boys whose muscles, tendons, ligaments and nerves have not fully matured yet (Malina, Bouchard, 1991).

Natural human movements, including various types of jumps, usually combine eccentric and concentric phases of muscle contraction and are referred to as stretch-shortening exercise (Avela et al., 1996). Stretching of the muscle-tendon complex just before the movement affects power generation (Ettema, 1997). It has been demonstrated that height of a vertical jump increases when the subject prestretches muscles by a countermovement, compared to the jump from the static semi-squat position (Häkkinen, Komi, 1983). This could be due to stretch reflex potentiation and utilisation of elastic energy stored in the series of elastic elements during the jump with the countermovement (Häkkinen, Komi, 1983). Stretch loads increase when subjects drop from $80 \mathrm{~cm}$ height and perform the so-called drop jump (Avela et al., 1996). Repetitive drop jumps have been used as means of power training in athletes (Bobbert, 1990). However, this type of exercise induces LFF as well (Skurvydas et al., 2000). The LFF is believed to be a major cause of performance deterioration during prolonged isometric exercise of submaximal intensity, but effects of LFF on power generation in brief contractions are less clear (Lucidi, Lehman, 1992; Ratkevičius et al., 1995). The LFF has been mainly studied in adult volunteers, and it is largely unknown how age affects muscle resistance to LFF which appears to be one of the major factors limiting muscle potential to generate force during prolonged repetitive exercise (Ratkevičius et al., 1995). Thus the aim of this study was to find out if LFF manifests itself in the muscles of boys aged 12-14 years doing 75 drop jumps performed every $20 \mathrm{~s}$ at angles of $90^{\circ}$ and $135^{\circ}$ from a platform $80 \mathrm{~cm}$ high.

\section{METHODS}

Subjects. Nine teenagers boys $(\mathrm{n}=12)$ $($ age $=13.1 \pm 0.6 \mathrm{yr}$, body height $=160.4 \pm 7.4 \mathrm{~cm}$, body mass $=46.4 \pm 5.9 \mathrm{~kg}$ ) took part in the study of fatigue in the lower leg muscles after repetitive drop jump exercise. After explanation of procedures, risks and benefits of the study written informed consent was obtained from the boys' parents and the boys. The boys were recruited from one of the local schools. The boys both participated in classes of physical activity two - three times a week and could be considered as physically active. However, none of the subjects was specializing in any form of sports training.

Isometric torque measurements. The isometric torque of knee extensor muscles was measured in a dynamometer as described previously (Ratkevičius et al., 1995; Skurvydas et al., 2000). The subjects sat upright in the dynamometer chair with both the hip and knee joints positioned at approximately $90-135$ degrees of flexion. For a recording of the knee extension torque, force transducer was connected to a lever arm and the pad of the lever arm was placed approximately $3 \mathrm{~cm}$ above malleoli. A belt joined to the force measuring device (UGO BASILE 7080 type DY 150 , Italy) was placed on the lower third part of the calf of the right leg. The output of the transducer was analogue-to-digital converted (12bit) at a sampling rate of $1000 \mathrm{~Hz}$ and stored on a computer hard disk for later off-line analysis. During the maximal isometric voluntary contraction (MVC), the output from the torque transducer was also displayed on a voltmeter in front of the subjects.

Electrical stimulation. Details of the equipment and procedure for electrical stimulation were essentially the same as previously described (Ratkevičius et al., 1995; Skurvydas et al., 2000). Tolerance of subjects to electrical stimulation was assessed on a separate occasion by testing different patterns of electrical stimulation. All subjects showed good compliance with the procedure when short trains of stimuli were applied at a progressively higher frequency up to $50 \mathrm{~Hz}$. During the subsequent experiment, the electrical stimulation was delivered with surface electrodes, placed over the quadriceps muscle, in 1 -s trains of stimuli using the current that induced (at $50 \mathrm{~Hz}$ ) $52-98 \% \mathrm{MVC}$, as measured from the subject on the day of testing. This electrical stimulation of muscles was performed at $1,10,15$, 20 and $50 \mathrm{~Hz}$ stimulation for $1 \mathrm{~s}$ at each frequency. During the off-line data analysis, peak torque was evaluated at each frequency. The $1-\mathrm{Hz}$ stimulation produced a single twitch. For the twitch, contraction time (CT) and half-relaxation time (RT 0.5) were measured. The CT was the 
time from the start of torque development until the point when the peak torque was reached. The RT 0.5 was the time from the peak torque until the point when torque decreased to a half of the peak torque value.

Drop jumps. Drop jumps were performed as previously described (Skurvydas et al., 2000). Firstly, each subject performed warming-up exercises that consisted of a 5-min running on the spot with an intensity that corresponded to a heart rate of $130-150$ beats $/ \mathrm{min}^{-1}$; then the subject performed 10 squat-stands and $2 \mathrm{~min}$ of rest were allowed. Thereafter, the subject performed 75 drop jumps from a height of $80 \mathrm{~cm}$ to an approximately $90^{\circ}$ angle in the knees in eccentric mode. One jump was performed every $20 \mathrm{~s}$. The actions of the subjects were discussed whith them in advance and they were told that after jump down with a squat the knee joint should be at $90^{\circ}$ angle. The subjects always climbed the $80 \mathrm{~cm}$ high platform with the left leg while force measurements were performed on the right leg.

Vertical jumps up. The control vertical jumps up with approximately $90^{\circ}$ angle in the knees were performed on a standard jump mat (Powertimer Testing System, Newtest, Tampere, Finland). As described by the producer, the Powertimer Testing System calculates jump height according to the time spent in the air (flying time) during the jump (Bosco et al., 1983; Komi and Bosco, 1978; Skurvydas et al., 2000).

Experimental procedure. The indices of muscle contraction and relaxation were registered at angles of $90^{\circ}$ and $135^{\circ}$ in the following sequence:

1. The power of muscle contraction evoked by a single electrical stimulus (single twitch- $P_{t}$ ), the duration of contraction up to a single twitch and half-relaxation time (RT 0.5) were measured.

2. This electrical stimulation of muscles was performed at 1, 10, 15, 20 and $50 \mathrm{~Hz}$ stimulation for $1 \mathrm{~s}$ at each frequency. The duration of stimulation was $1 \mathrm{~s}$ and rest intervals between stimulation impulses were $5 \mathrm{~s}$.

3. Maximal voluntary force (MVF) of muscle contraction - three trials performed every 3 5 min.

4. After non-intensive warming-up a slow running for 10 min was undertaken (pulse rate at the end of running had reached about 110 130 beats / $\mathrm{min}$ ), then followed three control jumps up of performed every $20 \mathrm{~s}$.

5. Jumping exercise consisted of 75 drop jumps performed every $20 \mathrm{~s}$ from a platform 80 high with a squat up to $90^{\circ}$ angle in the knees in the eccentric mode. The platform was mounted leaning on the left leg, i.e. not on the leg muscle function properties of which were being tested.

6. Immediately 3, 30 and 60 min after the exercise all indices of voluntary and involuntary contraction at angles of $90^{\circ}$ and $135^{\circ}$ were registered repeatedly. The height of standing vertical jump up 1 and 60 min after the exercise was registered too. Fatigue index (FI $=$ index value after exercise / index control value before exercise $\times 100$ per cent) of all index values was calculated. Besides, all indices of voluntary and involuntary contraction at angles of $90^{\circ}$ and $135^{\circ} 12$ and $24 \mathrm{~h}$ after the exercise were registered repeatedly. Jumping fitness and subjective muscle pain according to a 10-point scale were evaluated too.

Statistics. Descriptive data are presented as means \pm SD. The groups of boys were compared with a two-way analyses of variances (ANOVA). Statistical significance of all tests was set at $\mathrm{p}<0.05$. If significant effects were found, post hoc testing was performed applying paired t-tests with a Bonferroni correction for multiple comparisons. Statistical significance of all tests was set at $\mathrm{p}<0.05$.

\section{RESULTS}

Doing 75 jumps performed every $20 \mathrm{~s}$ did not bring about any changes $(p>0.05)$ in the height of vertical jump up that was statistically significantly $(\mathrm{p}<0.05)$ different from the initial value but $60 \mathrm{~min}, 12$ and $24 \mathrm{~h}$ after the exercise (Fig. 1). The boys felt muscle pain $(3.7 \pm 1.3$ points) $12 \mathrm{~h}$ after the exercise, and $24 \mathrm{~h}$ after the exercise the boys felt a greater muscle pain (5.4 \pm 1.7 points).

There is no correlation between the rate of decrease in the height of vertical jump up immediately after the exercise and muscle pain $12 \mathrm{~h}(-0.047)$ and $24 \mathrm{~h}(-0.051)$ after the exercise.

The values of the twitch, contraction time (CT) and half-relaxation time (RT 0.5) are presented in Fig. 2 and Fig. 3. There is a statistically significant $(p<0.05)$ difference in 
Fig. 1. Mean values in the height of vertical jump up before the exercise, immediately after it 1 (A 1), 60 (A 60) min, 12 (A 12) and 24 (A 24) $h$ after the jumping exercise

Note. * - there was a statistically significant difference in mean values of the same index immediately after the exercise $(\mathrm{p}<0.01)$.

Table 1. General characteristics and torque (in newtons) at different frequencies of electrical stimulation plus maximal voluntary contraction (MVC) in the force generating capacity test (FGCT) before exercise at $90^{\circ}$ and $135^{\circ}$ angles

Note. Pt is twitch peak torque; P 10, P 20 and P 50 stand for peak torques at $1,10,20$ and $50 \mathrm{~Hz}$ of electrical stimulation respectively; MVC is maximal voluntary contraction. Values are means $\pm \mathrm{SD}$.

Fig. 2. Mean values of duration of a single twitch muscle contraction time (CT) evoced by a single electrical impulse before the exercise, immediately after it 3 (A 3), 30 (A 30), 60 (A 60) min, 12 (A 12) and 24 (A 24) $h$ after the jumping exercise at angles of $90^{\circ}$ and $135^{\circ}$

Note. * - there was a statistically significant difference in mean values of the same index immediately after the exercise $(\mathrm{p}<0.05) ; \quad * *$ $\mathrm{p}<0.01$.

index values of CT (Fig. 2) and RT 0.5 (Fig. 3) after jumping exercise done at angles of $90^{\circ}$ and $135^{\circ}$. There is no statistically significant $(\mathrm{p}<0.05)$ difference in index values of $\mathrm{CT}$ at the $90^{\circ}$ angle $30 \mathrm{~min}, 12 \mathrm{~h}$ and $24 \mathrm{~h}$ after the exercise, when compared to the control values. There were similar regularities in the changes of $\mathrm{CT}$ values at the $135^{\circ}$ angle too (Fig. 2). There were statistically significant differences in index values of RT 0.5 at the $135^{\circ}$ angle immediately after the exercise, $30 \mathrm{~min}$ and $12 \mathrm{~h}$ after the exercise, compared to the initial value $(\mathrm{p}<0.05)$ but there was no statistically significant difference $60 \mathrm{~min}$,

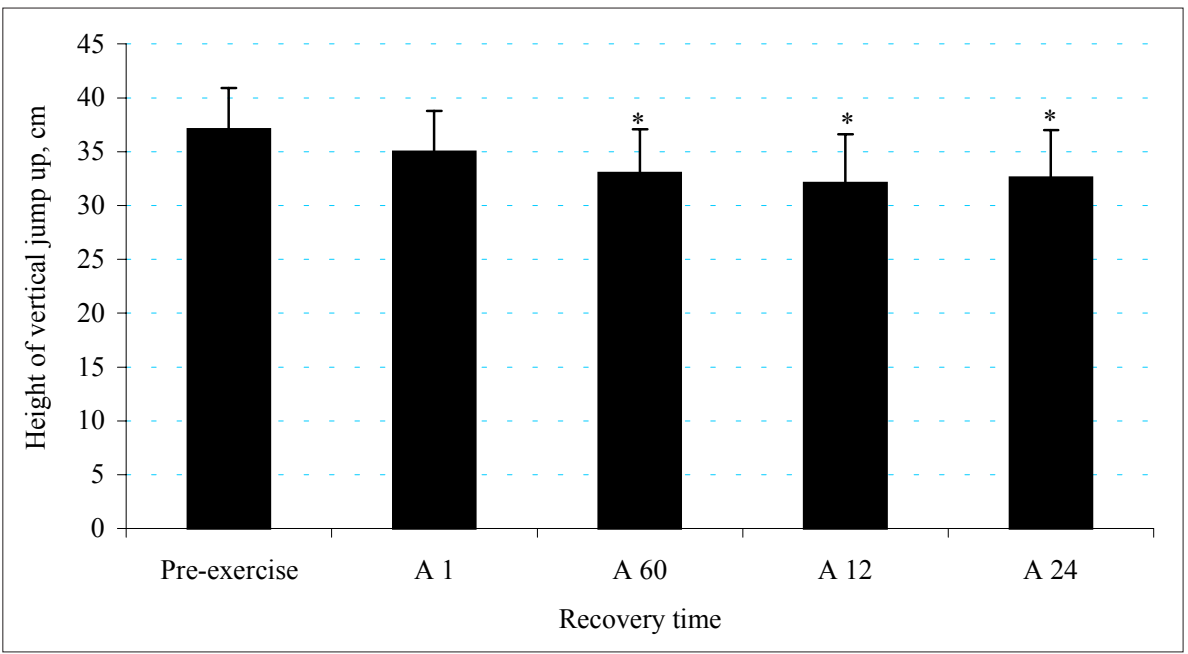

\begin{tabular}{|c|c|c|c|c|c|c|}
\hline $\begin{array}{c}\text { Muscle } \\
\text { length }\end{array}$ & Pt, N & P 10, N & P 20, N & P 50, N & P 20 / P 50 & MVC, N \\
\hline $90^{\circ}$ angle & $77.7 \pm 26.2$ & $165.9 \pm 37.6$ & $295.8 \pm 50.0$ & $345.2 \pm 50.9$ & $0.85 \pm 0.03$ & $500.4 \pm 43.8$ \\
\hline $135^{\circ}$ angle & $74.5 \pm 24.2$ & $137.8 \pm 31.7$ & $329.2 \pm 67.8$ & $408.6 \pm 67.5$ & $0.80 \pm 0.06$ & $527.3 \pm 51.8$ \\
\hline & $\mathrm{p}>0.05$ & $\mathrm{p}<0.05$ & $\mathrm{p}>0.05$ & $\mathrm{p}<0.05$ & $\mathrm{p}>0.05$ & $\mathrm{p}>0.05$ \\
\hline
\end{tabular}

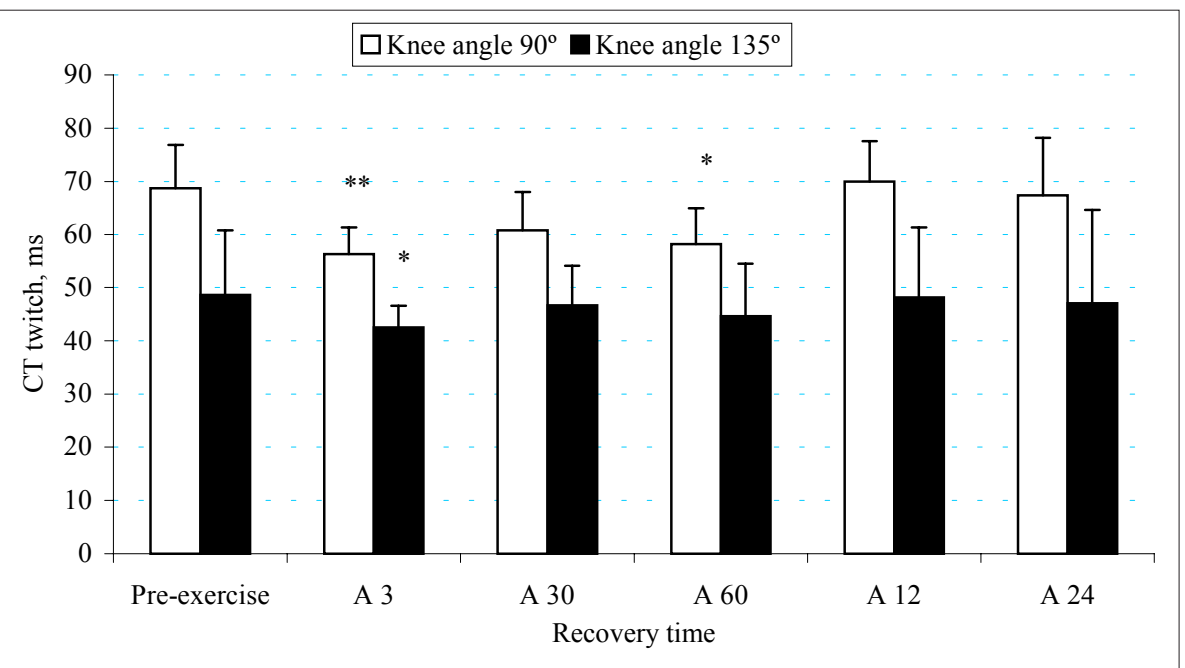

$24 \mathrm{~h}$ after the exercise comparing measurings made with initial values (Fig. 3). There was a statistically significant difference, howeer, at the $90^{\circ}$ angle immediately after the exercise, compared to the initial value $(p<0.05)$ but later the indices returned to their initial values (p > 0.05) (Fig. 3).

There was a significant decrease $(\mathrm{p}<0.001)$ in the values of Pt, P 10, P 20, and P 50 indices at angles of $90^{\circ}$ and $135^{\circ}$ after the jumping exercise. $\mathrm{Pt}, \mathrm{P} 10$, P 20, and P 50 indices did not return to the initial level $24 \mathrm{~h}$ later (Fig. 4 and Fig. 5), except $\mathrm{Pt}$ that had recovered $(\mathrm{p}>0.05) 24 \mathrm{~h}$ after 

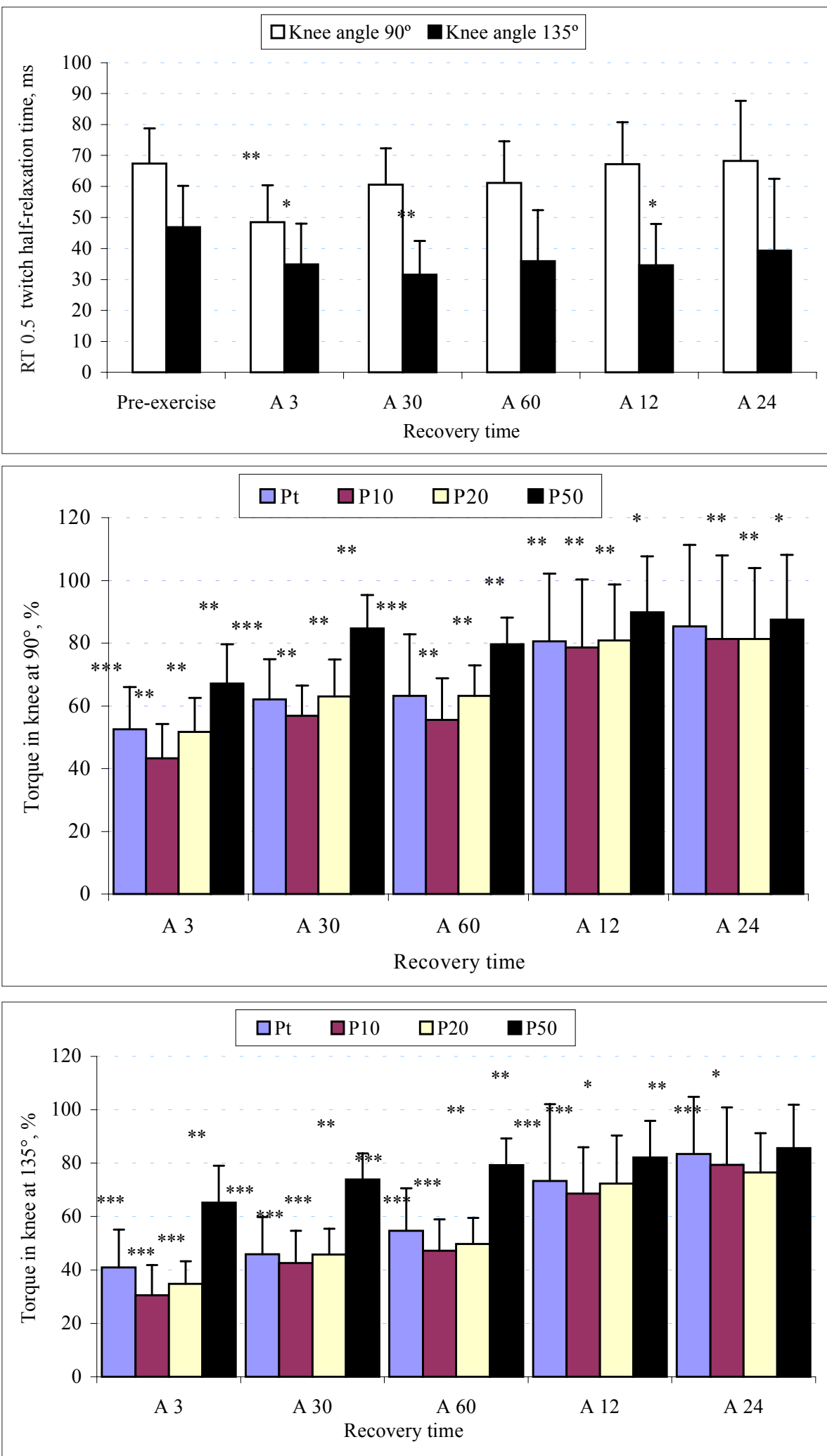

Fig. 3. Mean values of duration of a single muscle half-relaxation time (RT 0.5) evoced by a single electrical impulse before the exercise, immediately after it 3 (A 3), 30 (A 30), 60 (A 60) min, 12 (A 12) and 24 (A 24) $h$ after the jumping exercise at angles of $90^{\circ}$ and $135^{\circ}$

Note. * - there was a statistically significant difference in mean values of the same index immediately after the exercise $(p<0.05) ; * *$ $\mathrm{p}<0.01$.

Fig. 4. Mean values of duration of fatigue indices (FI) of muscle involuntary contraction at the angle of $90^{\circ}$. Pt, P 10, P 20 and $P 50$ index alternation immediately after the exercise 3 (A 3), 30 (A 30), 60 (A 60) $\mathrm{min}, 12$ (A 12) and 24 (A 24) $h$ after the exercise

Note. $*$ - there was a statistically significant difference in mean values of the same index immediately after the exercise $(\mathrm{p}<0.05) ; * *$ $\mathrm{p}<0.01 ; * * *-\mathrm{p}<0.001$.

Fig. 5. Mean values of duration of fatigue indices (FI) of muscle involuntary contraction at the angle of $135^{\circ}$. Pt, $P 10, P 20$ and $P 50$ index alternation immediately after the exercise 3 (A 3), 30 (A 30), 60 (A 60) $\mathrm{min}, 12$ (A 12) and 24 (A 24) $h$ after the exercise

Note. * - there was a statistically significant difference in mean values of the same index immediately after the exercise $(\mathrm{p}<0.05) ; * *$ $\mathrm{p}<0.01 ; * * *-\mathrm{p}<0.001$. exercise. There was a statistically significant decrease $(\mathrm{p}<0.001)$ in the $\mathrm{P} 20 / \mathrm{P} 50$ ratio already $3 \mathrm{~min}$ after the exercise both at the $90^{\circ}$ angle and $135^{\circ}$ angle. This is sure to indicate the presence of LFF (Fig. 6) the indications of which did not disappear, i. e. the indices of the P 20 / $P 50$ ratio did not reach their initial value even
$24 \mathrm{~h}$ after the exercise at the angle of $135^{\circ}$ but the indices $(p>0.05)$ had recovered at the angle of $90^{\circ} 24 \mathrm{~h}$ after the exercise. It is of interest to note that the repeated eccentric exercise brought about but slight changes in MVF indices (Fig. 7) that did not change statistically significantly $(p>0.05)$ already $3 \mathrm{~min}$ after physical exercise, decreased 
Fig. 6. Mean values of fatigue indices (FI) of the forces $P 20$ / $135^{\circ}$ immediately after the exercise 12 (A 12) and 24 (A 24) $h$ after the exercise

Note. * - there was a statistically significant difference in mean values of the same index immediately after $\mathrm{p}<0.01$. $P 50$ ratio at angles of $90^{\circ}$ and 3 (A 3), 30 (A 30), 60 (A 60) min, the exercise $(\mathrm{p}<0.05) ; * *$

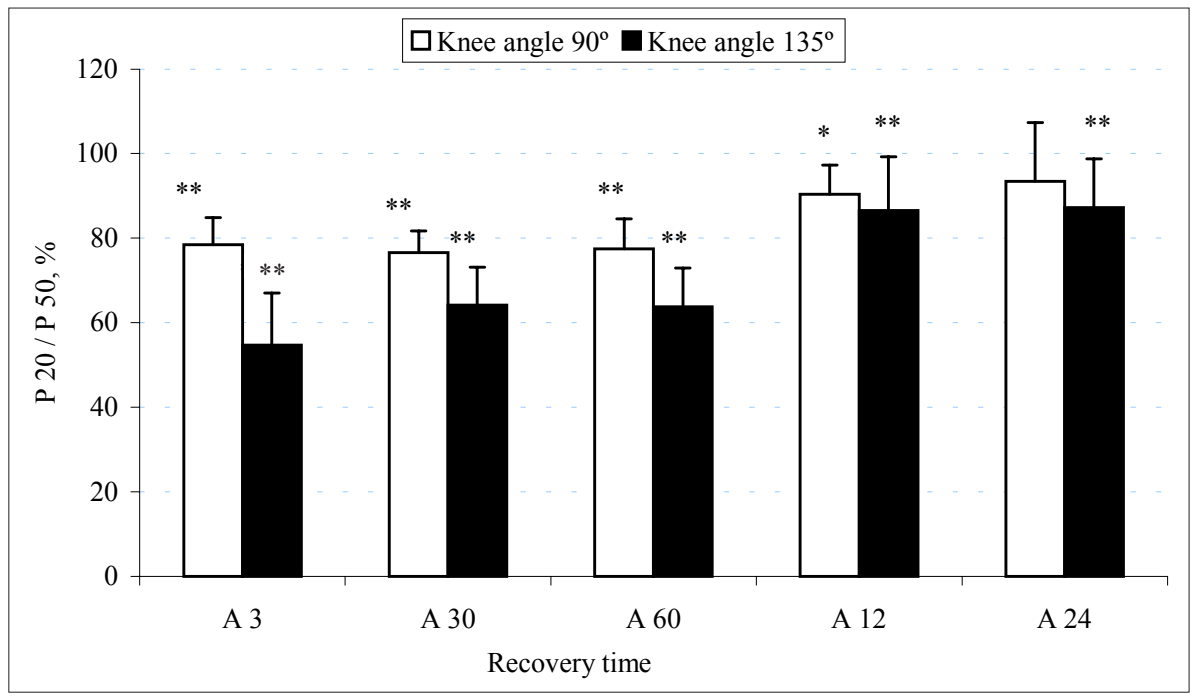

Fig. 7. Mean values of duration of fatigue indices (FI) of muscle voluntary contraction at angles of $90^{\circ}$ and $135^{\circ}$ immediately after the exercise 3 (A 3), 30 (A 30), 60 (A 60) min, 12 (A 12) and 24 (A 24) $h$ after the exercise
Note. * - there was a statistically significant difference in mean values of the same index immediately after the exercise $(\mathrm{p}<0.05)$.

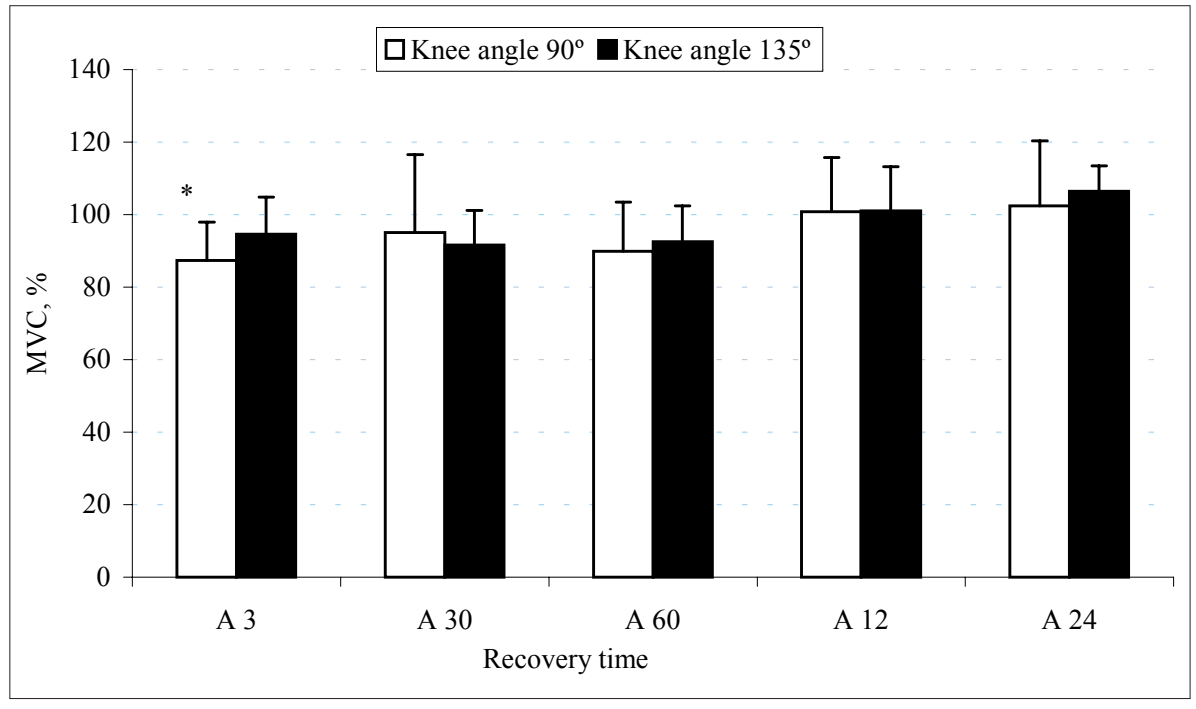

$(\mathrm{p}<0.05)$ at the angle of $90^{\circ}$ and recovered $(p>0.05)$ at the angle of $135^{\circ}$. Later there were no statistically significant changes $(\mathrm{p}<0.05)$ in MVF indices at both angles 30 min after physical exercise.

\section{DISCUSSION}

On the basis of the results obtained in the process of the research done the main conclusion could be made that doing 75 eccentric jumps performed every $20 \mathrm{~s}$ there was a statistically significant decrease in the values of both voluntary and involuntary contraction force and they did not return to their initial values (Fig. 4 and Fig. 5). Still there was a decrease in the values of separate indices. Thus, for example, the slightest changes (about 5.5\%) after the exercise had occurred in the height of vertical jump up and MVF at the $90^{\circ}$ and $135^{\circ}$ angle. There was a 20-
32 per cent decrease in the force (P 50) evoked by high stimulation frequencies at the $90^{\circ}$ angle and about $15-35$ per cent decrease at the $135^{\circ}$ angle accordingly. The greatest decrease (about 45\%) was in the force evoked by low stimulation frequencies at the $135^{\circ}$ angle (P 10 and P 20) and the same force at the $90^{\circ}$ angle had decreased from 20 to 55 per cent. Thus, it could be maintained that it was the so-called low frequency fatigue (LFF) that manifested in the muscles most markedly what is evident from a decrease in the value of the P 20 / P 50 ratio, particularly at a shorter muscle length, i. e. at the $135^{\circ}$ angle (Edwards et al., 1977). This corresponds to the results obtained by other scientists and is indicative of the fact that LFF mostly manifests itself doing unaccustomed, eccentric physical exercise in particular. It takes some time for the above-mentioned fatigue to disappear after the exercise and it is frequently accompanied by 
muscle pain (Armstrong et al., 1991; Jones et al., 1989).

In the case of our research there could not have been an accumulation of a great number of metabolites (unorganic phosphate, ADF, hydrogen ions, etc.) that decrease muscle contraction force in the muscle, since there was a sufficiently long period of time between the jumps performed for the ATP and $\mathrm{PCr}$ (phosphocreatine) to recover (Fitts, 1994). Therefore the reasons for the appearance of muscle fatique should not be looked for in muscle metabolism. It is believed that doing eccentric physical exercise may give rise to disintegration of sarcomeres and elastic muscle components, as well as proteins connecting the $\mathrm{T}$ system with sarcoplasmic reticulum (Armstrong et al., 1991; Jones et al., 1989) what can call forth a decrease not only in the force of myofibrillas but also in the number of $\mathrm{Ca}$ ions released from the sarcoplasmic reticulum (Fitts, 1994; Westerblad et al., 1993). This is considered to be the main cause of the rise of LFF. The same cause also forms the basis for the decrease in the force (P 50) evoked by high stimulation frequencies. Since in the case of high stimulation frequencies myofibrillas are saturated by $\mathrm{Ca}$ ions more fully a small change in $\mathrm{Ca}^{2+}$ concentration changes MCF but slightly (Westerblad et al., 1993).

Performing jumps may cause a decrease in the sensitiveness of reflexes that exert influence on the activity of motor neurons. For example, it has been established that an increased activity of afferents 3 and 4 can inhibit the jumping fitness of athletes. Besides, the sensitiveness of reflexes can also depend on changes in the elastic properties of the muscle during physical exercise. Since jumping fitness also depends on the use of the elastic properties of the muscle (Bosco et al., 1982 a) in the case of our exercise after warmingup of tendons and muscles, muscle elasticity might have been used to a greater extent.

Jumping fitness of boys aged $12-14$ years is similar to the results obtained by our earlier research (Skurvydas et al., 1999). Still it is much smaller than that of grown-up athletes and persons not going in for sports (Bosco, Komi, 1979; Bosco et al., 1982 a; Skurvydas et al., 1999). It is of interest to note that the value of the P 20 / P 50 ratio in the case of the boys studied by us is similar to that of grown-up persons not going in for sports (Ratkevičius et al., 1995).
Why is LFF smaller in boys aged 12-14 years than in grown-up persons when doing 75 jumps performed every $20 \mathrm{~s}$ ? We have not come across any studies testifying to the fact that, for example, doing physical exercises that give rise to LFF would decrease the amount of $\mathrm{Ca}^{2+}$ released from the sarcoplasmic reticulum in boys to a greater extent than in the case of grown-up men. Besides, it is not clear at all how such an exercise might cause a damage in the electromechanical connection between the T-system and the sarcoplasmic reticulum in the muscle of boys. It is thought that the duration of a single contraction depends on the number and rate of $\mathrm{Ca}$ ions released from the sarcoplasmic reticulum (Cannel, Allen, 1984). Since CT in boys immediately after the exercise comprised 82.7 per cent at the $90^{\circ}$ angle and 93.3 per cent at the $135^{\circ}$ angle of its control value and, according to the results of our research (Skurvydas et al., 1999), CT in men was about 75 per cent of its control value respectively, we think that in the case of boys a decrease in the number of $\mathrm{Ca}$ ions released from the sarcoplasmic reticulum took place. It might be considered, therefore, that our jumping exercise damaged not only the sarcoplasmic reticulum but also its connection with the $\mathrm{T}$ system less considerably. It is not likely that there was an essential change in the number of proteins (such as parvalbumin) absorbing $\mathrm{Ca}$ ions or in their sensitiveness to $\mathrm{Ca}$ ions. The LFF mechanism is not identified with this factor (Westerblad et al., 1993).

It has been established that when doing repeated dynamic exercise of high intensity children distinguish themselves by greater resistance to metabolic fatigue than grown-ups. It has also been established that boys recover sooner than men after intensive exercise of short duration since boys recruit anaerobic glycolysis to a smaller extent compared to men. Therefore acydosis in the muscle of boys manifests itself less considerably than in the case of men (Dotan et al., 2003). Unfortunately, there is still shortage of studies in the diferences of fatigue between children and grown-ups when doing physical exercises causing muscle damage (Duarte et al., 1999). Besides, we have not found any data in special literature about the effect of age on the exercise giving rise to metabolic fatigue and muscle damage.

The age of our subjects corresponds to the period of intensive growth of the body during 
which the muscles are subjected to both quantitative and qualitative changes (Malina, Bouchard, 1991; Swynghedauw, 1986). It has been established that during post-pubertal period a particularly intensive synthesis of sexual hormones takes place (Malina, Bouchard, 1991) and these hormones exert stronger influence in the synthesis of proteins of muscle fibres of the fasttwitch type (Johnson et al., 1994). There is also another opinion that in the course of body growth no changes in the ratio of muscle fibres of the fast-twitch and slow-twitch types take place (Eriksson et al., 1973; Komi and Bosco, 1978). Besides, it is thought that growth and maturation rates of motor units of different types do not coincide (Bell et al., 1980). Due to an increase in the number of viscous chains of miosin of the fast type the power of muscle contraction increases (Bell et al., 1980; Johnson et al., 1994). For example, the greater the number of muscle fibres of the fast-twitch type in the muscle the higher the jump height of the subjects (Bosco, Komi, 1979). Thus, it might be supposed that in the muscles of boys aged $12-14$ years muscle fibres of the fasttwitch type that possess more elastic components than fibres of the slow-twitch type have not completely matured yet (Eriksson et al., 1973; Malina, Bouchard, 1991). The muscles of boys of this age are known to be more elastic than those of grown-up men (Malina, Bouchard, 1991). All this allows one to suppose that the muscles of boys aged $12-14$ years are more resistant to LFF. Besides, boys could have mobilized themselves less when doing the jumping exercise, since it has been established (Belanger, McComas, 1989) that children and adolescents are capable of activating less motor units than grown-ups.

\section{CONCLUSIONS}

Doing eccentric physical exercises with submaximum intensity (jumping down from a platform $80 \mathrm{~cm}$ high) in the muscles of boys there arises low frequency fatigue that remains throughout $24 \mathrm{~h}$ and is greater at a short muscle length throughout the time tested.

\section{REFERENCES}

Armstrong, R. B., Warren, G. L., Warren, J. R (1991). Mechanisms of exercise-induced muscle injury. Sports Medicine, 12 (3), 184-207.

Avela, J., Santos, P. M., Komi, P. V. (1996). Effects of differently induced loads on neuromuscular control in drop jump exercise. European Journal of Applied Physiology, 72, 553-562.

Belanger, A. Y., McComas, A. J. (1989). Contractile properties of human skeletal muscle in childhood and adolescence. European Journal of Applied Physiology, 58, $563-567$.

Bell, R. D., McDougal, J. D., Bileter, R., Howald, H. (1980). Muscle fiber types and morphometric analysis of skeletal muscle in six year old children. Medicine and Science in Sports Exercise, 12, 28-31.

Bobbert, M. F. (1990). Drop jumping as a training method for jumping ability. Sports Medicine, 9, 7-22.

Bosco, C., Komi, P. (1979). Mechanical characteristics and fiber composition of human leg extensors muscles. European Journal of Applied Physiology, 41, 275-284.

Bosco, C., Luhtanen, P. and Komi, P. V. (1983). A simple method for measurement of mechanical power in jumping. European Journal of Applied Physiology, 50, 273-283.

Bosco, C., Tihanyi, J., Komi, P. V., Fekete, G., Apor, P. (1982 a). Store and recoil of elastic energy in slow and fast types of human skeletal muscles. Acta Physiologica Scandinavica, 116, 343-349.

Cannel, M. B., Allen, D. G. (1984). Model of calcium movements during activation in the sarcomere of forg skeletal muscle. Biophysical Journal, 45, 913-925.
Dotan, R., Ohana, S., Bediz, C., Falk, B. (2003). Blood lactate disappearance dynamics in boys and men following exercise of similar and dissimilar peak-lactate concentrations. Journal of Pediatric Endocrinology \& Metabolism, 16 (3), 419-429.

Duarte, J. A., Magalhaes, J. F., Monteiro, L., AlmeidaDias, A., Soares, J. M., Appeal, H. J. (1999). Exerciseinduced signs of muscle overuse in children. International Journal of Sports Medicine, 20 (2), 103-108.

Edwards, R. H. T., Hill, D. K., Jones, D. A., Merton, P. A. (1977). Fatigue of long duration in human skeletal muscle after exercises. Journal of Physiology, 272, 769-778.

Eriksson, B. O., Golnick, P. D., Saltin, B. (1973). Muscle metabolism and enzyme activities after training in boys 11-13 years old. Acta Physiologica Scandinavica, 87, $485-497$.

Ettema, G. J. C. (1997). Mechanical behaviour of rat skeletal muscle during fatiguing stretch shortening cycles. Experimental Physiology, 82, 107-119.

Fitts, R. H. (1994). Cellular mechanisms of muscle fatigue. Physiological Review, 74 (1), 49-94.

Friden, J., Lieber, R. L. (1992). Structural and mechanical basis of exercise-induced muscle injury. Medicine and Science in Sports Exercise, 24 (5), 521-530.

Häkkinen, K., Komi, P. V. (1983). Alterations of mechanical chracteristics of human skeletal muscle during strength training. European Journal of Applied Physiology, 50, 161-172.

Johnson, B. D., Wilson, L. E., Zhan, W. Z., Watchko, J. T., Daood, M. J., Sieck, G. C. (1994). Contractile properties 
of the developing diaphragm correlate with myosin heavy chain phenotype. Journal of Applied Physiology, 77 (1), $481-487$

Jones, D. A., Newham, D. J., Torgan, C. (1989). Mechanical influence on long-lasting human muscle fatigue and delayed-onset muscle pain. Journal of Physiology, 412, 451-427.

Jones, D. A., Round, J. A. (1997). Human muscle damage induced by eccentric exercise or repercussion injury: a common mechanism? In S. Salmons (Ed.), Muscle Damage (pp. 64-75). Oxford, New York, Tokyo: Oxford University Press.

Komi, P. V. and Bosco, C. (1978). Utilization of stored elastic energy in leg extensor muscles by men and women. Medicine and Science in Sports, 10, 261-265.

Komi, P. V., Karlsson, J. (1987). Skeletal Muscle fibre types, enzyme activities and physical performance in young males and females. Acta Physiologica Scandinavica, 103, 210-218.

Malina, R. M., Bouchard, C. (1991). Growth, Maturation and Physical Activity. Champaign, IL: Human Kinetics.

Newham, D. J., Mills, K. R., Quigley, B. M. \& Edwards, R. H. (1983). Pain and fatigue after concentric and eccentric muscle contractions. Clinical Science, 64 (1), 55-62.
Ratkevičius, A., Skurvydas, A. and Lexell, J. (1995). Submaximal-exercise-induced impairment of human muscle to develop and maintain force at low frequencies of electrical stimulation. European Journal of Applied Physiology, 70, 294-300.

Skurvydas, A., Jaščaninas, J. and Zachovajevas, P. (2000). Changes in height of jump, maximal voluntary contraction force and low-frequency fatigue after 100 intermittent or continuous jumps with maximal intensity. Acta Physiologica Scandinavica, 169, 55-62.

Skurvydas, A., Streckis, V., Streckienè, V. (1999). Berniukų ir vyru mažų dažnių nuovargio „sarkomerinès“ hipotezès patikrinimas. Ugdymas. Küno kultūra. Sportas, $3(32), 50-54$.

Stephensson, D. G., Wendt, I. R. J. (1984). Length dependence in sarcoplasmic calcium concentration and myifibrillar calcium sensitivity in striated muscle fibres. Muscle Research Cell Motility, 5, 243-272.

Swynghedauw, B. (1986). Developmental and functional adaptation of contractile proteins in cardiac and skeletal muscles. Physiological Review, 66, 710-771.

Westerblad, H., Duty, S., Allen, D. G. (1993). Intracellular calcium concentration during low-freguency fatigue in isolated single fibres of mouse skeletal muscle. Journal of Applied Physiology, 75, 382-388.
Vytautas Streckis

Lithuanian Academy of Physical Education Sporto str. 6, LT-44221 Kaunas

Lithuania

Tel +37068793839

E-mail v.streckis@lkka.lt 